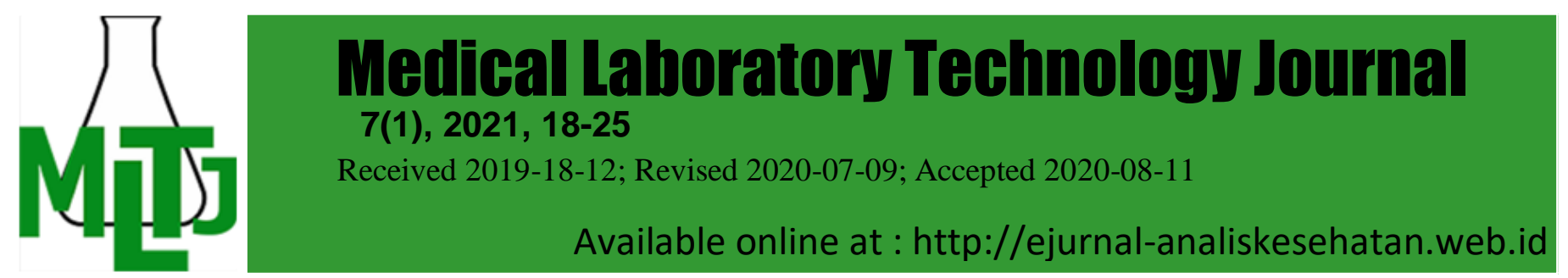

\title{
Autologous Stem Cell Transplantation in Multiple Myeloma Patients Over 60 Years Old
}

\author{
Bahar Uncu Ulu, Tuğçe Nur Yiğenoğlu, *Semih Başcı, Mehmet Bakırtaş, Derya \\ Şahin, Tahir Darçın, Jale Yıldız, Alparslan Merdin, Nuran Ahu Baysal, Dicle \\ İskender, Mehmet Sinan Dal, Merih Kızıl Çakar, Fevzi Altuntaş
}

Department of Hematology and Bone Marrow Transplantation Center, Ankara Dr. Abdurrahman Yurtaslan Oncology Training and Research Hospital, University of Health Sciences, Ankara, Turkey.

*E-mail: dr.semihbasci@gmail.com

DOI: $10.31964 / \mathrm{mltj} . v 0 \mathrm{i} 0.280$

\begin{abstract}
The incidence of Multiple myeloma (MM) increases with age; two-thirds of the patients are older than 65 years. Induction treatment, including new agents such as thalidomide, bortezomib, and lenalidomide followed by a conditioning regimen and upfront autologous stem cell transplantation (ASCT), has been accepted the standard treatment approach for newly diagnosed fit MM patients. We aimed to search the reallife data, the efficacy and safety of upfront ASCT following induction in patients with MM over 60 years old retrospectively. The data of MM patients who were $\geq 60$ years old during autologous stem cell transplantation and treated at our center between 2010 and 2018 retrospectively analyzed. The study results were 63 patients included at the age of $\geq 60$ years who underwent upfront ASCT. Median PFS was $15.5 \pm 2.6$ months, and the median overall survival (OS) was $28.15 \pm 5$ months. According to age groups, median PFS was $12 \pm 2.3$ months in the 60-64 age group, $18.4 \pm 6$ months in the $65-69$ age group, and $26 \pm 15$ months in the $\geq 70$ age group. Median OS was $26.5 \pm 6.1$ months in the 60-64 age group, 39.66 \pm 8.9 months in the 65-69 age group, and 18 months in the $\geq 70$ age group. A significant relationship between the quantity of infused CD34+ stem cells and PFS and OS ( $\mathrm{p:0.05}$ and $\mathrm{p}<0.00$, respectively). Our study indicated that a high dose $\left(200 \mathrm{mg} / \mathrm{m}^{2}\right)$ melphalan could safely be used in the physically fit patients at the ages of $60-69$, and a reduced amount $\left(140 \mathrm{mg} / \mathrm{m}^{2}\right)$ would be the appropriate dose for the patients over 70. The quantity of infused CD34+ stem cells affect elderly MM patients; mobilization dynamics are also important factors for elderly myeloma. Age itself should not consider a barrier to ASCT, and a comprehensive geriatric evaluation should perform on elderly patients.
\end{abstract}

Keyword: Autologous stem cell transplantation; elderly; multiple myeloma; upfront; 60 years old

\section{INTRODUCTION}

Multiple myeloma (MM) is a plasma cell malignancy in which clonal plasma cells produce monoclonal immunoglobulins. MM patients usually present with skeletal destruction with osteolytic lesions and pathologic fractures, hypercalcemia, renal insufficiency, and anemia. MM accounts for $10 \%$ of hematological neoplasms (Rajkumar SV,2018). Incidence of MM increases with age; the median age at diagnosis is 70 years, two-thirds of the patients are older than 65 years (Palumbo A, 2012; Harousseau JL, 2008; Mina R, 2019).

Induction treatment including novel agents such as proteosome inhibitors (bortezomib) or immunomodulators (thalidomide, lenalidomide) followed by upfront 
autologous stem cell transplantation (ASCT) has been accepted as the standard treatment approach for newly diagnosed fit MM patients (Palumbo A, 2012; Harousseau JL, 2008; Mina R, 2019). Chronological age alone does not constitute an obstacle for the conditioning regimen of hematopoietic stem cell transplantation (Klepin HD, 2006; Cavo M, 2011; Manupuram S, 2018).

Autologous stem cell transplantation may also consider for physically fit elderly patients with no comorbidities; however, MM patients over 70 years old are not seen appropriate for high dose conditioning due to toxicities, impairments of organ functions, decreased drug metabolisms, and increased risk of frailty by the advanced age (Palumbo A, 2012; Harousseau JL, 2008; Klepin HD, 2006; Cavo M, 2011; Mina $R$, 2019) Hence, most of the randomized clinical trials comparing ASCT and conventional chemotherapy have excluded elderly patients (Cavo M, 2011; Wildes TM, 2014; McCarthy PL, 2013; Mina R, 2019). In the absence of randomized studies, the safety, efficacy, and toxicities of ASCT in MM patients aged $\geq 65$ years are still uncertain (Mizuno S, 2019).

Over the past two decades, the rate of adults older than 70 years undergoing ASCT increased more than five-fold, from less than $1 \%$ to nearly $5 \%$ (McCarthy PL, 2013; Manupuram S, 2018). Several cohort studies compared the survival and response rates in patients younger vs. elderly for ASCT. The studies showed that lower doses of melphalan (100-140 mg $\left./ \mathrm{m}^{2}\right)$ would be appropriate for MM patients up to 75 years-old for ASCT conditioning (Facon T, 2007; Palumbo A, 1999; Badros A, 2001). Moreover, in another phase III trial, melphalan and prednisolone plus thalidomide (MPT) were superior to conditioning with melphalan $\left(100 \mathrm{mg} / \mathrm{m}^{2}\right)$ in patients between 65 and 75 years of age (Facon T, 2007). A careful assessment should identify eligible elderly patients for ASCT, regardless of their chronological age (Klepin HD, 2006; Mizuno S, 2019). In the era of the increasing use of upfront ASCT after induction therapy with novel agents in MM elderly patients, we aimed to search the real-life data, the efficacy and safety of upfront ASCT in MM patients over 60 years old our center retrospectively.

\section{MATERIALS AND METHOD}

Data of MM patients older than 60 years old who underwent transplantation at Dr. Abdurrahman Yurtaslan Ankara Oncology Training and Research Hospital between 2010 and 2018 were retrospectively analyzed. The local ethics committee approved the study of our center (2019-09/399). All patients received a novel agent of proteasome inhibitors, bortezomib, with cyclophosphamide and dexamethasone named as 'VCD' for induction therapy. Patients are classified into three different age groups (60-64, 65-69, and $\geq 70$ years). Patients that $<70$ years old administered 200 $\mathrm{mg} / \mathrm{m}^{2}$ melphalan for conditioning of ASCT, whereas patients that 70 years and above received $140 \mathrm{mg} / \mathrm{m}^{2}$ melphalan. The melphalan dose was reduced to $140 \mathrm{mg} / \mathrm{m}^{2}$ for patients with serum creatinine levels of $\geq 2.0 \mathrm{mg} / \mathrm{dL}$ before conditioning. Patients mobilized with $10 \mu \mathrm{g} / \mathrm{kg}$ subcutaneous granulocyte-colony stimulating factor (G-CSF) in 2 divided doses $(2 \times 5 \mathrm{mcg} / \mathrm{kg})$. Patients who a mobilization failure with G-CSF alone mobilize with high dose cyclophosphamide $\left(4.000 \mathrm{mg} / \mathrm{m}^{2}\right)$ plus G-CSF. In the third step, the patient could not mobilize with a high dose of cyclophosphamide $(4.000 \mathrm{mg}$ $/ \mathrm{m}^{2}$ ) plus G-CSF; mobilization performed using plerixafor plus G-CSF. Peripheric blood-derived stem cells with a continuous blood separator flow (Fresenius Kabi, COM.TEC, Germany). A total volume of 150 to $400 \mathrm{~mL} / \mathrm{kg}$ blood process for each apheresis at a flow rate of 50 to $60 \mathrm{~mL} / \mathrm{min}$. The tandem transplant patients in the study; described the second ASCT 6 months after the first ASCT without any 
progression or relapse. Durie Salmon (DS) and the International Staging System (ISS) were used for risk classification (Greipp PR, 2005).

During ASCT, neutropenia, defined as absolute neutrophil count (ANC), was < $500 / \mathrm{mm}^{3}$, and thrombocytopenia as platelet counts $<20000 / \mathrm{mm}^{3}$. The engraftment definition for neutrophil define as the first day when the absolute neutrophil count (ANC) was $>500 / \mathrm{mm}^{3}$ or $1000 / \mathrm{mm}^{3}$ for three consecutive days, and thrombocyte engraftment describes as the first day when thrombocyte count was $>20000 / \mathrm{mm}^{3}$ for three straight days without transfusion. All patients received weight adapted G-CSF before the neutrophil engraftment. The treatment response evaluates the criteria of the International Multiple Myeloma Working Group (IMWG) (Durie BG, 2006). Complete response (CR) define as negative immunofixation in serum and urine, lack of plasmacytomas, and less than $5 \%$ plasma cells in the bone marrow. A reduction in serum $M$ protein of $\geq 50 \%$ is considered a partial response (PR). Progression (PD) defines as an increase of at least $25 \%$ in measurable monoclonal immunoglobulin in serum or urine or a rise of $\geq 25 \%$ in urinary light chains. If CR lasts in less than three months, it defines progress (PD) (Durie BG, 2006). Overall survival (OS) describes the duration from the date of transplantation to death or the latest follow-up date for the survivors. Progression free survival (PFS) defines as the duration from the date of transplantation to the progress in disease, death, or date of the latest follow-up for progression-free patients, whichever occurred first. Transplant-related mortality (TRM) was the cumulative death in the first 100 days after allogeneic stem cell transplantation without any evidence of disease progression.

All statistical analyses conducted using SPSS V21.0 (SPSS Inc., Chicago, IL) software. Descriptive statistics were applied to summarize the data. The categorical data report as rates, and numeric data report as medians and average \pm standard deviations. The Kruskal Wallis Test was used to analyze engraftment times between the groups. Kaplan Meier test uses to analyze PFS and OS, and the log-rank test applied for the survival impacting factors.

\section{RESULTS AND DISCUSSION}

Sixty-three MM patients included who underwent ASCT at the age of 60 or older at our center. The patients' clinical and demographic features give in Table 1. 46 patients consisting of 24 females and 22 males included in the 60-64-year-old group. The 65-69-year-old group included five female and eight male patients, a total of 13 patients. There were four patients in $\geq$ the 70 -year-old group. Pre-transplant disease status evaluated that $36 \%$ were in CR, $28 \%$ were VGPR, $30 \%$ were PR, and $4 \%$ were in stable and progressive disease. Disease status three months after ASCT were $73 \%$ CR, $4.8 \%$ VGPR, $14.2 \%$ PR, and $1.5 \%$ progressive disease. We could not obtain the response evaluation results in $6.5 \%$ of the patients from the data. $24(38 \%)$ patients received one line, 31 (49\%) patients received 2 line chemotherapy, and eight patients $(6 \%)$ received 3 line chemotherapy before ASCT. The dose of conditioning chemotherapy for ASCT decided for the age and creatinin, and 12 (19\%) patients received $140 \mathrm{mg} / \mathrm{m}^{2}$ melphalan, and 51 (81\%) patients received $200 \mathrm{mg} / \mathrm{m}^{2}$ melphalan.

Median PFS was $15.5 \pm 2.6$ months, and the median OS was $28.15 \pm 5$ months. According to age groups, median PFS was $12 \pm 2.3$ months in the 60-64 age group, $18.4 \pm 6$ months in the 65-69 age group, and $26 \pm 15$ months in the $\geq 70$ age group. Median OS was 26.5 \pm 6.1 months in the 60-64 age group, 39.66 \pm 8.9 months in the 6569 age group, and 18 months in the $\geq 70$ age group (Table 2 ). The survival rates dinot 
differ according to the age groups (p:0.463 for PFS; $p: 0.62$ for OS ). TRM observes in only 1 case (at the age of 64).

Median neutrophil engraftment duration was 11 days in 60-64 and 65-69 age groups and 12 days in $\geq 70$ age group. Median thrombocyte engraftment duration was 12 days in 60-64 and 65-69 age groups and 11 days in $\geq 70$ age group. The period of both neutrophil and thrombocyte engraftment did not differ according to the age groups. In the univariant and multivariant analysis, the relationship between OS, PFS, and gender, age groups, MM subgroups, disease stages, the number of therapy lines received, radiotherapy, the dose of conditioning regimen they received, the quantity of infused CD34+ stem cells, the disease status before and after transplantation give in Table 3.

42 of 63 patients mobilize with $10 \mu \mathrm{g} / \mathrm{kg}$ subcutaneous granulocyte-colony stimulating factor (G-CSF) in 2 divided doses $(2 \times 5 \mathrm{mcg} / \mathrm{kg})$. Seven patients had a mobilization failure with G-CSF alone; they mobilized with high dose cyclophosphamide $\left(4.000 \mathrm{mg} / \mathrm{m}^{2}\right)$ plus G-CSF afterward. One patient could not mobilize with a high dose of cyclophosphamide $\left(4.000 \mathrm{mg} / \mathrm{m}^{2}\right)$ plus G-CSF. In this patient, mobilization performed using plerixafor plus G-CSF. The mobilization method of 13 patients could not reach from the records.

Table 1. Patients' the clinic and demografic characteristics

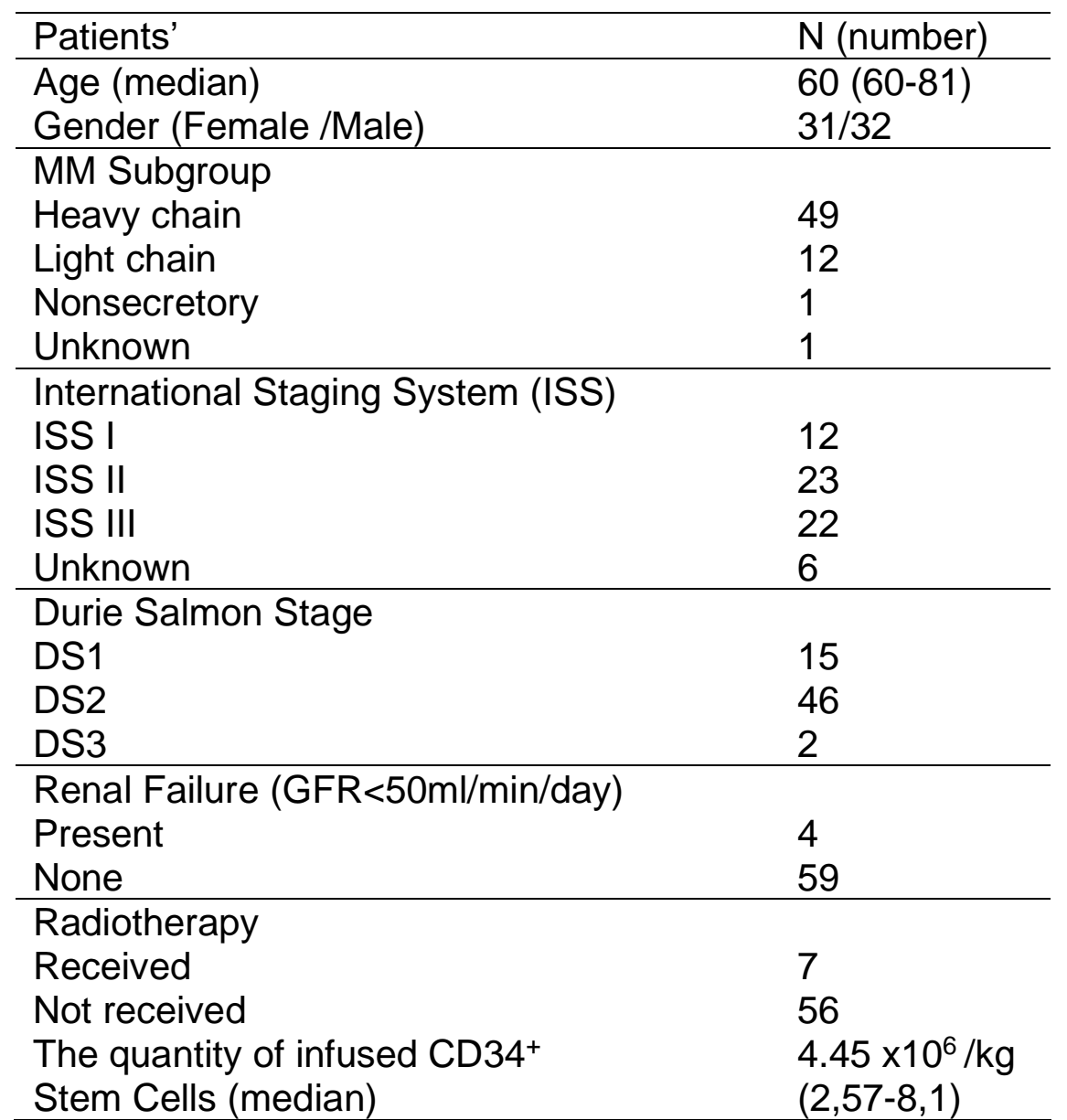

Abbreviations: M:multiple myeloma, ISS: International Staging System, DS: Durie Salmon, GFR: glomerular filtration rate, min:minute 
Table 2: Progression-Free-Survival and Overall Survival between Age Groups

\begin{tabular}{lllll}
\hline Survival & $60-64$ years & $65-69$ years & $\geq 70$ years & $p$ value* \\
\hline $\begin{array}{l}\text { Progression-free } \\
\text { Survival (months) }\end{array}$ & $12 \pm 2,3$ & $18,4 \pm 6$ & $26 \pm 15$ & 0,463 \\
$\begin{array}{l}\text { Overall Survival } \\
\text { (months) }\end{array}$ & $26,5 \pm 6,1$ & $39,6 \pm 8,9$ & 18 & 0,620 \\
*Kaplan Meier test was used to analyze & PFS and OS and p value using SPSS V21.0
\end{tabular}

Table 3: Factors Impacting Progression-Free-Survival and Overall Survival

\begin{tabular}{|c|c|c|}
\hline Impacting Factors & $\begin{array}{l}\text { Progression-Free } \\
\text { Survival (PFS) } \\
\text { p value }^{\mathrm{a}}\end{array}$ & $\begin{array}{l}\text { Overall Survival } \\
\text { (OS) } \\
\text { p value }\end{array}$ \\
\hline $\begin{array}{l}\text { The quantity of infused median CD34+ } \\
\text { Stem Cells }\end{array}$ & $\mathrm{p}: 0.05^{\star}$ & $p<0.001^{* *}$ \\
\hline ISS & p: 0,716 & p: $0.041^{*}$ \\
\hline Gender & p: 0,304 & p: 0,810 \\
\hline Age Groups & p: 0,463 & p: 0,620 \\
\hline MM subgroup & p: 0,587 & p: 0,984 \\
\hline $\begin{array}{l}\text { Melphalan dose } \\
\left(140 \mathrm{mg} / \mathrm{m}^{2} \text { vs } 200 \mathrm{mg} / \mathrm{m}^{2}\right)\end{array}$ & p: 0,115 & p: 0,578 \\
\hline Number of chemotherapy lines & p: 0,434 & p: 0,272 \\
\hline Radiotherapy & p: 0,224 & p: 0,501 \\
\hline Pre-transplant disease status & p: 0,767 & p: 0,054 \\
\hline Post-transplant disease status & p: 0,268 & p: 0,811 \\
\hline
\end{tabular}

Abbreviations:ISS: International Staging System, MM: multiple myeloma,

a: the log-rank test was applied for the survival impacting factors $p$ value using SPSS V21.0. ${ }^{*} p$ value $<0.05 ;{ }^{* *} p$ value $<0.001$

A significant relationship between the quantity of infused CD34+ stem cells and PFS and OS (p:0.05 and p<0.001, respectively); the amount of infused CD34+ stem cells affects OS mostly. While we did not find any relationship between the ISS stage and PFS, we found a statistically significant relationship between the ISS stage and OS (p:0.041).

Over the last two decades, very significant advances in the treatment of MM have developed. With the improvement of supportive care, the rate of MM patients receiving ASCT over the age of 70 increased to $25 \%$ in 2004-2005 that it was $6 \%$ in 1994-1995 (McCarthy PL, 2013). The mobilization of hematopoietic stem cells is inadequate for elderly patients, and a higher number of apheresis procedures are required (Morris CL, 2003; Micallef IN, 2013). However, an adequate amount of hematopoietic stem cells can collect in most elderly patients using plerixafor or high dose cyclophosphamide in mobilization (Morris CL, 2003; Micallef IN, 2013). In our study, we observed that only one patient had mobilization failure. Unlike other studies, we showed that the quantity of infused median CD34 + stem cells was an essential factor affecting survival in the elderly patient group in our study. Patients with better bone marrow reserves and adequate stem cell mobilization can prolong survival regardless of age. Our recent study has reported that low mobilizer myeloma patients have poor overall survival (Yiğenoğlu TN, 2020). Consequently, mobilization dynamics 
are also important factors affecting the survival of eligible elderly myeloma patients. Since there are no prospective trials and optimal melphalan doses for ASCT in the elderly MM group, a dose reduction strategy seems reasonable for melphalan over 70 years of age, so our study supports this data.

Age is not the only criterion for ASCT; thus, comorbidities and toxicities also essential issues. Evaluating performance status, liver, renal, pulmonary functions, history of infection, psychosocial support, patients preferences are the most important criteria for considering ASCT in elderly patients. Before developing a treatment plan for elderly patients, a comprehensive geriatric evaluation should perform on these patients(McCarthy PL, 2013).

In the majority of the studies conducted with the elderly populations, melphalan administered in lower doses. Some studies on ASCT consolidation in elderly MM patients (Gay F,2013; Straka C,2012; Kumar SK, 2013). In the survey conducted by Gay et al., in patients between 65 and 75 years old, induction with four courses of bortezomib, liposomal doxorubicin, and dexamethasone, followed by tandem ASCT (conditioning dose is $100 \mathrm{mg} / \mathrm{m}^{2}$ melphalan for each) and consolidation therapy with four courses of lenalidomide and dexamethasone; then maintenance performed with lenalidomide alone, the median PFS found 48 months and 5-year OS was 63\% (Gay $F, 2013)$. In previous studies, TRM found in $19 \%$ of MM patients over 70 years of age and $4 \%$ in patients under 70 years of age (Gay F,2013; Straka C,2012; Kumar SK, 2013). In the study conducted by Stettler et al., while single-day $200 \mathrm{mg} / \mathrm{m}^{2}$ melphalan was given to patients under the age of 70 as a conditioning regimen, $140 \mathrm{mg} / \mathrm{m}^{2}$ melphalan give to the patients over 70, and no TRM was observed (Palumbo A, 1999; Stettler J, 2016). The study conducted by Palumbo et al., it found that TRM was $19 \%$ in the patients with $200 \mathrm{mg} / \mathrm{m}^{2}$ melphalan group, whereas it was $0 \%$ at the dose of 100 $\mathrm{mg} / \mathrm{m}^{2}$ melphalan, and $2 \%$ at the amount of $140 \mathrm{mg} / \mathrm{m}^{2}$ melphalan (Palumbo A, 1999). On the other hand, in our study, all the patients over 70 were given $140 \mathrm{mg} / \mathrm{m}^{2}$ melphalan as a conditioning regimen. We did not find any difference between MM patients for PFS, OS, and TRM, patients in the 60-69 age group give melphalan 140 $\mathrm{mg} / \mathrm{m}^{2}$, and patients give $200 \mathrm{mg} / \mathrm{m}^{2}$. This finding supports the fact that melphalan dose reduction in conditioning regimen is not required in the physically fit patients at the ages of 60-69 with no renal failure and comorbidity. Similarly, ASCT with 200 $\mathrm{mg} / \mathrm{m}^{2}$ perform on the MM patients at the ages of 60-69, and no TRM report in the study conduct by Stettler et al. (Stettler J, 2016).

When the Center for International Blood and Marrow Transplant Research (CIBMTR) analyzed $11430 \mathrm{MM}$ patients that performed ASCT between 2008 and 2011 , they found that 3 -year PFS and OS were $42 \%$ and $78 \%$ respectively in patients of the $18-59$-age group, $38 \%$ and $75 \%$ in patients of the $60-69$-age group, and $33 \%$ and $72 \%$ respectively in patients of $\geq 70$ years group. In their study, the older the age contained, the lower the survival rate (Sharma M, 2014). Transplant-related mortality in our study is consistent with the literature. However, because of the retrospective design of our study after an eight-year follow-up between 2010 and 2018, we were unable to assess the transplant-related toxicity in detail from the data and did not use any fragility scorings for elderly patients. We evaluated patients' eligibility for transplantation based on performance scores and organ dysfunction. The developing fragility scores should be used for daily practice in the assessment of transplantation eligibility. 


\section{CONCLUSION}

In conclusion, our study indicated a high dose $\left(200 \mathrm{mg} / \mathrm{m}^{2}\right)$ melphalan could be safely used in physically fit patients between the ages of 60-69. A reduced dose (140 $\mathrm{mg} / \mathrm{m}^{2}$ ) would be the appropriate dose for the patients over 70 . The quantity of infused CD34+ stem cells affects elderly MM patients; mobilization dynamics are also important for elderly myeloma. Age itself should not consider a barrier to ASCT, and a comprehensive geriatric evaluation should perform on older MM patients.

\section{CONFLICT OF INTEREST}

The authors have nothing to disclose.

\section{REFERENCE}

Badros A, Barlogie B, Siegel E, et al. (2001). Autologous stem cell transplantation in elderly multiple myeloma patients over the age of 70 years. Br J Haematol. 2001, 114,600-607.

Cavo M, Rajkumar SV, Palumbo A et al. (2011) International Myeloma Working Group consensus approach to the treatment of multiple myeloma patients who are candidates for autologous stem cell transplantation. Blood, 117, 6063-6073.

Durie BG, Harousseau JL, Miguel JS et al. (2006). International uniform response criteria for multiple myeloma. Leukemia, 20, 1467-1473.

Facon T, Mary JY, Hulin C et al. (2007). Melphalan and prednisone plus thalidomide versus melphalan and prednisone alone or reduced-intensity autologous stem cell transplantation in elderly patients with multiple myeloma (IFM 99-06): a randomised trial. Lancet, 370, 1209-1218.

Gay F, Magarotto V, Crippa C, et al. (2013). Bortezomib induction, reduced-intensity transplantation, and lenalidomide consolidation-maintenance for myeloma: updated results. Blood, 122, 1376-1383.

Greipp PR, San Miguel J, Durie BG et al. (2005). International staging system for multiple myeloma. J Clin Oncol, 23, 3412-3420.

Harousseau JL. (2008) Autologous transplantation for multiple myeloma. Ann Oncol, 19 (Suppl 7): vii128-vii133.

Klepin HD, Hurd DD. (2006). Autologous transplantation in elderly patients with multiple myeloma: are we asking the right questions? Bone Marrow Transplant, 38, 585-592.

Kumar SK, Dispenzieri A, Lacy MQ, et al. (2013). Continued improvement in survival in multiple myeloma: changes in early mortality and outcomes in older patients. Leukemia, 28, 1122-1128.

Manapuram S, Hashmi H. (2018). Treatment of Multiple Myeloma in Elderly Patients: A Review of Literature and Practice Guidelines. Cureus, 10(12), e3669

McCarthy PL, Hahn T, Hassebroek A, et al. (2013). Trends in use of and survival after autologous hematopoietic cell transplantation in North America, 1995-2005: significant improvement in survival for lymphoma and myeloma during a period of increasing recipient age. Biol Blood Marrow Transplant, 19, 1116-1123.

Micallef IN, Stiff PJ, Stadtmauer EA, et al. (2013). Safety and efficacy of upfront plerixafor + G-CSF versus placebo + G-CSF for mobilization of CD34(+) hematopoietic progenitor cells in patients $\geqslant 60$ and $<60$ years of age with nonHodgkin's lymphoma or multiple myeloma. Am J Hematol, 88, 1017-1023.

Mizuno, S., Kawamura, K., Hanamura, I. et al. (2019). Efficacy and safety of autologous stem cell transplantation in patients aged $\geq 65$ years with multiple myeloma in the era of novel agents. Bone Marrow Transplant, 54, 1595-1604 
Morris CL, Siegel E, Barlogie B, et al. (2003). Mobilization of CD34+ cells in elderly patients ( $>/=70$ years) with multiple myeloma: influence of age, prior therapy, platelet count and mobilization regimen. Br J Haematol, 120, 413-423.

Palumbo A, Cavallo F. (2012). Have drug combinations supplanted stem cell transplantation in myeloma? Hematology Am Soc Hematol Educ Program, 2012, 335-341.

Palumbo A, Gay F, Falco P et al. (2010). Bortezomib as induction before autologous transplantation, followed by lenalidomide as consolidation-maintenance in untreated multiple myeloma patients. J Clin Oncol, 28, 800-807.

Palumbo A, Triolo S, Argentino C et al. (1999). Dose-intensive melphalan with stem cell support (MEL100) is superior to standard treatment in elderly myeloma patients. Blood, 94, 1248-1253.

Rajkumar, SV. (2018). Multiple myeloma: 2018 update on diagnosis, riskstratification, and management. Am J Hematol, 2018, 93, 1091-1110.

Sharma M, Zhang MJ, Zhong X, et al. (2014). Older patients with myeloma derive similar benefit from autologous transplantation. Biol Blood Marrow Transplant, 20, 1796-1803.

Stettler J, Novak U, Baerlocher GM, et al. (2017). Autologous stem cell transplantation in elderly patients with multiple myeloma: evaluation of its safety and efficacy. Leukemia \& Lymphoma, 58(5), 1076-1083.

Straka C, Schaefer-Eckart K, Bassermann F, et al. (2012). Prospective randomized trial of Len/Dex induction followed by tandem MEL 140 with autologous blood stem cell transplantation and Len maintenance versus continued therapy with Len/Dex in myeloma patients age 60-75 years: protocol-defined safety analysis after 100 patients. Blood, 120, 2012. doi: 10.1155/2014/394792.

Wildes TM, Rosko A, Tuchman SA. (2014). Multiple myeloma in the older adult: better prospects, more challenges. J Clin Oncol, 32(24), 2531-2540.

Yiğenoglu TN, Basçı S, Ulu BU, et al. (2020). Inferior prognosis in poor mobilizing myeloma patients. Transfusion and Apheresis Science, 59(3), 102722; Doi: 10.1016/j.transci.2020.102722 